\title{
SZTUKA, NIE ROPA. ARTYSTYCZNY AKTYWIZM KOLEKTYWU LIBERATE TATE
}

\author{
Art not oil. Art activism by Liberate Tate
}

\begin{abstract}
In her article the author analyses the activity of Liberate Tate collective, which was founded in 2010 with the aim to end sponsorship of Tate Gallery by BP oil company. This example of alliance between art and activism may be considered in two ways: in the context of the relationship between the institution and the artists who attempt to transform the museums, and also through the art of protest against the oil corporation responsible for environment exploitation. The activity of Liberate Tate is compared with others forms of protest, such as Occupy Wall Street or the fight against Dakota Access Pipeline. The framework of interpretation is indicated by the complex reliance between art, activism and neoliberal capitalism. The ideas of delirium and resistance proposed by Gregory Sholette appear to be particularly useful in explaining the given relations, as well as the notion of practicing deindividualization by activists, who build various alliances and communities of those engaged in creating the envisioned museum.
\end{abstract}

Keywords: Liberate Tate, art activism, art of protest, capitalocene, institutional critique

Dziesiątki czarnych balonów wypełnionych helem uniosły w górę martwe zwierzęta i zapełniły przestrzeń Hali Turbin Tate Modern w jednym z pierwszych performansów grupy Liberate Tate Dead in the water. Celem rozpoczętej w 2010 roku aktywności kolektywu było doprowadzenie do zerwania stosunków sponsorskich łączących sieć galerii Tate ${ }^{1} \mathrm{z}$ koncernem British Petroleum (BP). Grupą kierowała niezgoda na nadmierną eksploatację środowiska przez przemysł naftowy oraz strategię współpracy z instytucjami kultury, wykorzystywaną w celu uszlachetnienia wizerunku jego czołowych firm.

Początek wsparcia Tate przez BP przypadł na lata 90. XX wieku, które stanowiły okres rozbuchanego neoliberalizmu i braku szerszej refleksji na temat jego kosztów

1 W ramy Tate wchodzą: Tate Modern, Tate Gallery, Tate Liverpool, Tate St Ives. 
społecznych. Decyzja o końcu relacji sponsorskiej została ogłoszona w 2016 roku. Aktywna krytyka finansowego patronatu rozpoczęła się natomiast w 2010 roku, po wybuchu ogólnoświatowego kryzysu gospodarczego, którego szczyt przypadł dwa lata wcześniej. Przybliżam te ramowe daty, aby zasygnalizować obszar interpretacji artywizmu² Liberate Tate, jakim są zależności pomiędzy sztuką, aktywizmem i oporem a współczesnym wymiarem kapitalizmu. Umiejscowienie fenomenu grupy w kontekście neoliberalnej rzeczywistości pozwala na określenie jej wpływu na pozycję artystów w ramach systemu sztuki, a także na analizę strategii podejmowanych po to, by z nim walczyć.

Grupa Liberate Tate zawiązała się w podczas warsztatów poświęconych sztuce oraz aktywizmowi organizowanych przez Tate Modern ${ }^{3}$ i zakończonych umieszczeniem baneru Sztuka, nie ropa na najwyższej kondygnacji muzeum. Powstanie kolektywu zainicjował gest cenzorski: sugestia organizatorów wydarzenia, by w ramach działań warsztatowych pomijać krytykę samej Tate oraz jej relacji sponsorskich, sprowokowała artystów do rozwijania właśnie tej ścieżki aktywizmu. Nawiązała się wówczas specyficzna forma komunikacji pomiędzy instytucją a jej adwersarzami. Każda decyzja Tate (lub jej brak) wywoływała odpowiedź aktywistów/artywistów, przygotowywaną $\mathrm{w}$ języku sztuki i w bezpośrednim odniesieniu do historii i programu galerii. Była to wyrafinowana sztuka nakłaniania instytucji do własnych racji.

Na przykład we wrześniu 2010 roku w rocznym raporcie opublikowanym przez Tate podkreślano, że zrównoważony rozwój pełni zasadniczą rolę w programie placówki, a także pochwalono się ograniczeniem emisji węgla i współpracą z organizacją Carbon Trust, wspierającą zrównoważoną politykę gospodarczą ${ }^{4}$. W tym samym miesiącu, a dzień przed zebraniem Rady Nadzorczej Tate, 50 członków kolektywu rozlało w Hali Turbin smugi czarnej farby, tworząc z niej kształt przypominający solarny logotyp koncernu BP. Praca zatytułowana Crude lub też Sunflower zapowiadała jednocześnie wystawę Ai Weiweia Sunflower Seeds, którą pokazywano we wnętrzach galerii w kolejnych miesiącach. Wystawę-instalację znanego z politycznego zaangażowania artysty tworzyła masa z milionów porcelanowych nasion słonecznika zapełniających przestrzeń Hali Turbin, które można interpretować między innymi jako odnośnik do geopolitycznej złożoności kryjącej się za hasłem Made in China.

2 Terminem ,artywizm” posługuję się za Florianem Malzacherem, który połączył idiom „,artystyczny aktywizm” w jedno słowo, definiujące sojusze sztuki i aktywizmu oraz podkreślające ,przydatność artystycznych umiejętności, narzędzi, taktyk i strategii dla osiągnięcia aktywistycznych celów”, zob. F. Malzacher, Pisuar wraca do ubikacji. Symboliczna i bezpośrednia moc sztuki, w: S. Herbst, F. Malzacher (red.), Prawda jest konkretna. Artystyczne strategie w polityce. Podręcznik, Fundacja Bęc Zmiana, Warszawa 2018, s. 14.

3 J. Jordan, On Refusing to Prebend to Do Politics in a Museum, http://www.artmonthly.co.uk/magazine/site/article/on-refusing-to-pretend-to-do-politics-in-a-museum-by-john-jordan-2010 (dostęp: 11.08.2018).

4 Tate Report 2009-2010, https://www.tate.org.uk/download/file/fid/17029, s. 50 (dostęp: 20.08.2018). 
Podobnie, gdy dyrekcja Tate konsekwentnie odmawiała ujawnienia kwot kryjących się za sponsorską relacją z BP, kolektyw przygotował performans Hidden Figures (2014), reinterpretujący obraz Kazimierza Malewicza Czarny kwadrat, prezentowany w tym czasie w Tate Modern ${ }^{5}$. Ikoniczna dla historii sztuki figura straciła stabilną formę na rzecz zmiennej materii - falującej tkaniny, podatnej na choreografię i ruchy poruszających nią osób. Trzyletni spór wokół udostępnienia danych dotyczących wsparcia finansowego udzielanego przez BP, który angażował firmy prawnicze i pozarządowe organizacje, zakończył się wyrokiem sądowym zmuszającym Tate do upublicznienia informacji. Ujawnione zaskakująco niskie kwoty donacji ${ }^{6}$ sprowokowały artystów do rozrzucenia specjalnie zaprojektowanych banknotów $B P$ /Tate w przestrzeni wystawy powstałej przy wsparciu koncernu zatytułowanej $B P$ Walk through British Art (praca The Reveal, 2015).

\section{Negocjując instyłucje}

Liberate Tate współtworzy historię kolektywnie współpracujących artystów skupionych na przekształceniu struktur instytucji sztuki, takich jak Art Workers Coalition, Black Emergency Cultural Coalition, Guerilla Girls czy powstałe w przeciągu ostatnich kilku lat Occupy Museum i Gulf Labor Artist Coalition. Ponadto współdzieli cel zerwania sponsorskich zależności łączących instytucje sztuki z przemysłem naftowym wraz z siostrzanymi inicjatywami, takimi jak BP or not BP? oraz Fossil Free Culture NL.

Tematyka działań podejmowanych przez Liberate Tate pozwala na włączenie grupy w ramy krytyki instytucjonalnej, a więc kontestacyjnej analizy wielowymiarowego funkcjonowania instytucji sztuki, która skupia się na finansowym i politycznym uzależnieniu galerii Tate oraz rozbieżnościach pomiędzy deklarowaną a ucieleśnioną misją placówki. Liberate Tate wielokrotnie punktowała hipokryzję instytucji oraz jej pozornie inkluzyjny charakter; jak miało to miejsce na przykład podczas performansu The Gift (2012), kiedy stuosobowa grupa zainstalowała we wnętrzu Hali Turbin blisko 17-metrową łopatę turbiny wiatrowej i przekazała ją do kolekcji galerii. Ta, mimo środowiskowego wsparcia dla darowizny, odrzuciła ją. Głównym punktem krytyki ze strony Liberate Tate pozostaje jednak powiązanie z koncernem naftowym, którego działania prowadzą do nieodwracalnych zmian środowiska. Zależność ta występuje w jawnej opozycji do etycznych standardów i społecznej odpowiedzialności

Na wystawie Malevich, 16.07-26.10.2014.

6 W przeciągu 17 lat Tate otrzymała od koncernu 3,8 miliona funtów, czyli średnio 224 tysiące funtów rocznie. Jest to niewielka kwota, reprezentująca jedynie $0,5 \%$ zysku operacyjnego muzeum. Zob. https://www.theguardian.com/artanddesign/2016/mar/11/bp-to-end-tate-sponsorship-climate-protests (dostęp: 10.08.2018). 
muzeum, wymieniającego wśród swoich priorytetów między innymi zrównoważony model operacyjny?

Wpisanie Liberate Tate w obszar krytyki instytucjonalnej pozwala na uchwycenie wyróżniającego aspektu strategii perswazji obranej przez kolektyw. Krytyka instytucjonalna opisywana jest jako nurt lub gatunek sztuki, który w pełni ujawnił się w latach 60. XX wieku, lub też jako stała funkcja pola sztuki, ,rodzaj lustra kontrolnego, niezbędnego do właściwego życia instytucji"». Jednak przyjęcie drugiej definicji osłabia potencjał krytyczny praktyki artystycznej, podkreślając jej uwikłanie w system, który stara się kontestować. Przechyla wektor zainteresowania ku samemu polu sztuki oraz mechanizmom przechwytywania potencjału działań artystów, czy inaczej - inkorporowania otrzymanej krytyki w sposób, który sugeruje niemal samokrytyczną postawę praktykowaną przez instytucje.

Przemiany te najlepiej obrazuje pierwsza fala ruchu krytykującego świat sztuki, zapoczątkowana w latach 60. i 70. XX wieku przez artystów takich jak Marcel Broodthaers, Daniel Buren czy Hans Haacke. Ujawnienie ideologicznego uwikłania instytucji, zakłócenie triady kurator - artysta - odbiorca, a także tradycyjnych hierarchii dyktujących sposoby prezentacji i interpretacji sztuki pojawiło się w publicznym dyskursie między innymi dzięki ich twórczości. I zostało natychmiast wcielone w życie przez instytucje, które częściowo zaaplikowały dyskutowane zagadnienia, na przykład przekształcając własne strategie wystawiennicze. Pomimo zmian zachowały jednak hegemoniczną pozycję w polu sztuki, ponieważ to właśnie one prezentują prace wspomnianych artystów i tym samym kształtują kontekst twórczości krytycznej.

Aby doprecyzować charakter przemian w polu sztuki, warto przywołać klasyczne już rozważania Andrei Fraser, kwestionującej podział na instytucjonalny i pozainstytucjonalny obieg sztuki na rzecz złożonej struktury, która obejmuje i przenika wszystkie części składowe systemu (muzea i galerie, kolekcjonerów, artystów, akademie sztuki itd. $)^{9}$. Jednak, jak pokazywali artyści klasyfikowani w ramy drugiej fali krytyki instytucjonalnej, przypadającej na lata 80. i 90. XX wieku, między innymi Fred Wilson i James Luna, jest to system oparty na nierównościach, przestrzeń nieustannych zmagań głosów wykluczonych o uzupełnienie dominującej narracji.

Zdolność instytucji do podlegania metamorfozom, zwłaszcza pod wpływem krytycznych nacisków, wydaje się punktem wyjścia i nadzieją kolektywu Liberate Tate. Przyjmowana przez niego strategia to zniuansowana metoda „konia trojańskiego”, opisana w klasycznym już tekście Lucy Lippard ${ }^{10}$. Aktywiści nie tyle wpisują się

Zob. https://www.tate.org.uk/about-us/our-priorities (dostęp: 3.09.2018).

8 M. Ujma, Krytyka instytucjonalna, http://magdalena-ujma.blogspot.com/2013/01/krytyka-instytucjonalna.html (dostęp: 2.07.2018).

9 A. Fraser, From the Critique of Institutions to an Institution of Critique, „Artforum” 2005 (September), vol. 44 , iss. 1 , s. $278-283$.

10 L.R. Lippard, Trojan Horses: Activist Art and Power, w: B. Wallis (red.), Art after Modernism: Rethinking Representation, New Museum of Contemporary Art, New York 1984. 
w narrację tworzoną przez instytucję, ile przechwytują ją, a następnie poddają transformacji i prezentują odbiorcom w zmienionej formie.

Taktykę upodobniania się zapowiada już emblemat kolektywu, który jest wyrazistszą formą rozmytego logotypu Tate $\mathrm{z}$ dodanym dopowiadającym hasłem Liberate. Partyzanckie interwencje aktywistów wyglądają tak, jakby były częścią programu Tate. Często rozgrywają się w przestrzeni Hali Turbin, która od 2008 roku poświęcona jest sztuce współczesnej, powstającej na zamówienie muzeum. Postronnemu obserwatorowi akcji trudno rozpoznać konflikt różnicujący grupę aktywistów i instytucję, którą krytykują; obie należą do tego samego porządku sztuki i posługują się tym samym językiem. Mówią jednak coś innego. Liberate Tate wydaje się opierać strategię właśnie na tym napięciu. Aktywiści pozornie wypowiadający się w imieniu Tate dokonują przesunięcia semantycznego w tworzonym przekazie. Pozytywna, w przekonaniu dyrekcji Tate, współpraca sponsorska z koncernem BP ujawnia kontrowersyjne oblicze dzięki interwencjom kolektywu. Publiczne demonstrowanie problematycznej zależności oraz potencjalne uwikłanie Tate w autorstwo tego przekazu przypomina podszeptywanie instytucji instrukcji działania z nadzieją, że ta ją zinternalizuje. To praktykowanie mimikry, rozumianej jako taktyka subwersywnego kamuflażu ${ }^{11}$.

Przywołanie klasycznej teorii Homiego Bhabhy, rozwiniętej w obszarze studiów postkolonialnych, wydaje się szczególnie użyteczne z perspektywy niniejszego wywodu. Bhabha umieszcza bowiem analizę mimikry w kontekście negocjowania formuły reprezentacji. Podkreśla ambiwalentny charakter mimikry, uobecniający się w geście imitacji, na mocy której upodabniający staje się prawie taki sam jak jego punkt odniesienia, jednak nie całkiem. Upodabnianie nie jest więc prostym aktem kopiowania, ale strategią destabilizującą tożsamość podmiotów zaangażowanych w imitację. Najważniejsze w procesie mimikry jest „ześlizgiwanie się znaczenia”, a więc przekształcenie wzorów będących przedmiotem naśladownictwa ${ }^{12}$.

\section{Przeciw kapitalocenowi}

Kolektyw Liberate Tate włącza się w monolog instytucji wypowiadającej się przez kolekcję, wystawy oraz towarzyszące im programy - i go uzupełnia. „Dopowiedzenia” wykonywane na poziomie gestu i interwencji unaoczniają, że muzeum nie jest ani niewinne, ani neutralne. Grupa nie nastawia się jednak wobec galerii wrogo czy też opozycyjnie. Uprawiana przezeń sztuka perswazji bazuje nie tylko na piętnowaniu zależności sponsorskich, ale również na akcentowaniu wartości publicznej in-

11 Podobnego rozpoznania mimikry - jako wyróżnika strategii podejmowanej przez grupę aktywistek Guerilla Girls - dokonała Anna Teresa Demo w: The Guerrilla Girls' Comic Politics of Subversion, „Women's Studies in Communication” 2000, vol. 23, s. 132-156

12 H. Bhabha, Mimikra i ludzie. O dwuznaczności dyskursu kolonialnego, przeł. T. Dobrogoszcz, „Literatura na Świecie" 2008, nr 01-02 (438-439), s. 184-195. 
stytucji, które członkowie grupy uznają za pozytywne (takie jak idea powszechnego udostępniania sztuki) ${ }^{13}$.

Równolegle do uprawiania krytyki instytucjonalnej grupa atakuje koncern BP, obrazując katastrofalne skutki funkcjonowania przemysłu naftowego. W tym przypadku postawa Liberate Tate jest zdecydowanie konfrontacyjna i oparta na sztuce protestu budującego jasny i jednoznaczny komunikat dotyczący degradacji środowiska. W pierwszą rocznicę największej klęski ekologicznej w historii Stanów Zjednoczonych, czyli eksplozji platformy wiertniczej Deepwater Horizon (zarządzanej przez koncern BP) i wycieku ropy do Zatoki Meksykańskiej, przeprowadzono performans w Duveen Galleries w Tate Britain, w czasie którego nagiego, skulonego mężczyznę zalewano cieczą przypominają ropę (Human cost, 2011). W trzecią rocznicę katastrofy członkowie grupy zgromadzeni w przestrzeni Tate Modern wyszeptywali fragmenty transkrypcji procesu sądowego poświęconego wypadkowi (All Rise, 2013). Podczas performansu Floe Piece (2012) czteroosobowa grupa przetransportowała 55-kilogramowy blok lodu z siedziby ruchu protestacyjnego Occupy London w katedrze Świętego Pawła do Hali Turbin w Tate Modern. Następnie w milczeniu obserwowała topniejącą taflę. Obraz kosztów działalności koncernów naftowych tworzony przez Liberate Tate jest dosadny: tworzą go martwe zwierzęta, topniejący lód i ciała bezbronne wobec trujących substancji.

Oprotestowywana przez aktywistów korporacja metonimicznie reprezentuje siły kapitalocenu, odpowiedzialne za kształt nowej epoki geologicznej, której nazwa została wypracowana niejako w opozycji do określenia ,,antropocen”. Choć oba terminy odnoszą się do „ery człowieka” i jego destrukcyjnego wpływu na środowisko, to jednak wskazują na odmienne źródła epoki, jej główne siły i możliwe warianty rozwiązania. Etymologia słowa antropocen (łac. anthropos) sugeruje, iż odpowiedzialność za zmiany ponosi cały gatunek ludzki, zaś ich początek datowany jest na rewolucję przemysłową. Z kolei kapitalocen precyzyjniej identyfikuje „winnego” katastrofy ekologicznej - wskazuje na rolę kapitalizmu, a także na konkretny historyczny moment, zapowiadający i umożliwiający jego rozwój. Amerykański socjolog Jason Moore za kluczowe uznaje procesy zachodzące w XVI wieku, na mocy których wykształciła się binarna opozycja natura-kultura, czyniąca z natury rzecz podatną na eksploatację. Jak twierdzi Moore, natura „stała się tania [cheapened], ponieważ wciągnięto ją w procesy wymiany i zysku, przewalutowano i poddano kontroli" ${ }^{14}$.

13 M. Evans, K. Smith, Liberate Tate Activists Look Back on Six Years of Fighting BP Sponsorship. Interview by Benjamin Sutton, https://hyperallergic.com/288254/liberate-tate-activists-look-backon-six-years-of-fighting-bp-sponsorship/ (dostęp: 10.07.2017). W podobnym tonie i w szerszym kontekście opisuje nastawienie artystów Gregory Sholette: „Instytucjonalna władza przyciąga nawet swoich oponentów, być może dlatego, że ją kochamy lub przynajmniej kochamy jej projektowany, bezinteresowny obraz". G. Sholette, Delirium and Resistance: Activist Art and the Crisis of Capitalism, Pluto Press, London 2017, s. 34.

14 R. Patel, J. Moore, Tania natura, przeł. A.W. Nowak, P. Czapliński, w: P. Czapliński et al. (red.), O jeden las za daleko. Demokracja, kapitalizm i nieposhuszeństwo ekologiczne w Polsce, Instytut Wydawniczy Książka i Prasa, Warszawa 2019, s. 315. 
Badacz zwraca również uwagę na rolę nauki i systemów filozoficznych wspierających kolonizację natury (na przykład kartezjańskiego racjonalizmu), które - co warto dodać - w późniejszych wiekach legitymizowano i propagowano w instytucjach muzealnych.

Inicjatywy podejmowane przez artywistów z Liberate Tate znalazły szeroki oddźwięk społeczny, co potwierdza między innymi liczba jej członków - sięgająca 500 osób, które w różnym stopniu i w różnych momentach zaangażowane były w działalność grupy ${ }^{15}$. Akcje kolektywu wielokrotnie opisywano na łamach czasopism takich jak „The Guardian”, „The Independent” czy „The Times”. Wydarzeniem, które przyciągnęło międzynarodowe zainteresowanie mediów, był performans License to Spill ${ }^{16}$. Aktywiści zakłócili wówczas celebrację 20. rocznicy wspierania sztuki przez koncern BP, wylewając wśród tłumu gości przybyłych, by świętować długoletnią współpracę, setki litrów cieczy przypominającej ropę.

Widoczność realizowanych działań z pewnością była jednym z czynników determinujących skuteczność kolektywu. Aby obraz nadużyć w sferze środowiska wzbudził pożądany rezultat, musiał dotrzeć do jak największej grupy odbiorców. Interwencje artystów były więc „fotogeniczne”, odgrywane przez wizerunkowo ujednolicone postaci przyodziane w czarne kolory i wyposażone w często powtarzające się rekwizyty, takie jak kanistry oleistej cieczy. Powstałe obrazy były oszczędne stylistycznie, stanowily kontrast dla przestrzeni galeryjnej.

Siostrzana dla Liberate Tate grupa Fossil Free Culture NL, której aktywizm przyczynił się do zerwania sponsorskich relacji łączących Van Gogh Museum z Royal Dutch Shell, opisując strategie własnego działania, jednoznacznie zwraca uwagę na jego medialny potencjał. Członkowie grupy doradzają tworzenie pięknych obrazów, traktowanie performansów jak utworów filmowych oraz wykorzystywanie prac wideo, które stanowią potężne narzędzie mediów społecznościowych ${ }^{17}$. Jednym z elementów aktywizmu jest więc możliwe szerokie rozprzestrzenianie obrazów kapitalocenu oraz, co równie istotne, zapobieganie ich przeoczeniu przez odbiorców. Aby wiedza dotycząca skutków działalności człowieka mogła znaleźć swoje praktyczne zastosowanie (czyli wstrzymanie dalszej eskalacji), musi zostać zaabsorbowana, przyswojona, dosłownie ucieleśniona ${ }^{18}$.

W trakcie 25-godzinnego performansu Time Piece (2015) kilkudziesięciu aktywistów zapisywało węglem podłogę Hali Turbin hasłami dotyczącymi przekształceń

15 M. Evans, K. Smith, op. cit.

16 Ibidem.

17 Fossil Free Culture NL, Disobedient Art Can Win the Fight against Artwashing, https://gofossilfree. org/disobedient-art-wins-the-fight-against-artwashing/(dostęp: 20.09.2018). W kontekście nowoczesnych technologii wizualnych - zob. N. Mirzoeff, Jak zobaczyć świat, przeł. Ł. Zaremba, KarakterMuzeum Sztuki Nowoczesnej, Warszawa 2016.

18 Temat katastrofalnych skutków przekształceń środowiska spotykał i wciąż spotyka się z brakiem uznania bądź odrzuceniem przez wiele środowisk, uznających go za nierealne i wyolbrzymione zagadnienie. 
środowiska, przemysłu naftowego, sztuki i aktywizmu. Podczas najbardziej radykalnej akcji Birthmark (2015) kilkudziesięciu aktywistów zajęło przestrzeń galerii sztuki 1840 w Tate Britain na kilka dni przed otwarciem Konferencji Narodów Zjednoczonych w sprawie zmian klimatu, organizowanej w Paryżu. Wzajemnie tatuowali sobie trzycyfrowe numery, wskazujące na koncentrację dwutlenku węgla w atmosferze w roku ich urodzenia ${ }^{19}$. Setki osób podążyło za gestem artystów i również wpisało we własne ciała minimalistyczny tatuaż czcionką przypominającą typografię maszyny do pisania.

„Zmiana klimatu jest permanentna, tak jak tatuaże. Liczby są zapisane na ciele, firmy sponsorskie są zapisane na galerii, szkody spowodowane uwalnianiem węgla do atmosfery są zapisane na planecie"20 - tak opisują projekt członkowie kolektywu. Proces zapisywania symbolu owych zmian na ,ciele instytucji” i ciałach ludzkich jest więc metonimicznym odtworzeniem stanu faktycznego i jednocześnie czynnikiem mobilizującym do jego internalizacji, która rodzi określone skutki. Tekst zapisu, co symptomatyczne, zniknął z przestrzeni galerii w przeciągu kilku godzin, jednak performans okazał się ostatnią akcją poprzedzającą ogłoszenie decyzji o zerwaniu finansowych zależności pomiędzy Tate a BP. Został również powtórzony rok później, podczas wystawy BP Portrait Award, organizowanej w National Portrait Gallery, wciąż dotowanej przez koncern naftowy. Zapis pozostanie w trwałej, niezmienionej formie na ciele ochotników. Dosłowne ucieleśnianie wiedzy dotyczącej wpływu ludzkiej aktywności na ekosystem okazało się więc gestem, który w wyjątkowy sposób zaangażował odbiorców. Wytatuowanie liczby określającej zawartość dwutlenku węgla $\mathrm{w}$ atmosferze $\mathrm{w}$ roku urodzenia stanowiło, jak możemy przeczytać na profilach instagramowych uczestników, ,zobowiązanie, by brać pod uwagę środowiskowe konsekwencje działań i ich nieodwracalny wpływ na planetę” oraz „silne fizyczne przypomnienie" o tym, że liczby rosną i tracą na aktualności.

\section{Strategie antykapitalistycznego sprzeciwu}

Opisane metody protestu warto zestawić z innymi formami oporu i porównać projektowane przez nie wizje przyszłości po kapitalocenie.

T.J. Demos, historyk i krytyk sztuki, w tekście The Great Transition: The Arts and Radical System Change opisuje protesty przeciwko budowie rurociągu Dakota Access Pipeline w okolicy rezerwatu Standing Rock w Stanach Zjednoczonych, prowadzone głównie przez rdzennych mieszkańców Ameryki, zmagania działaczy ekologicznych grupy ZAD blokujące budowę strefy lotniskowej w okolicy francu-

19 Aktywiści wśród źródeł inspiracji wymieniają m.in. performance Mary Cobe Note to Self, w ramach którego artystka wytatuowała na swym ciele nazwiska 436 ofiar zamordowanych z powodu nieheteronormatywności.

20 Zob. http://www.liberatetate.org.uk/birthmark/ (dostęp: 1.09.2018). 
skiego Nantes, a także działania kolektywu Liberate Tate ${ }^{21}$. Demos analizuje metody obierane przez aktywistów do walki z oprotestowywanym przeciwnikiem: użycie luster odbijających obraz przemocy - uzbrojonych kordonów policji gotowych na starcie ze społecznością broniących rezerwatu; drony dokumentujące ruchy służb; ulotki i plakaty projektowane przez grafików i masowo wprowadzane do publicznego obiegu; szerzenie wiedzy; budowanie sojuszy wsparcia i poszerzenie kręgu aktywistów. Nazywa je praktykami antykolonialnej wizualności (practices of anticolonial visuality), wskazując na ich narzędziowy status i rebeliancki cel. Wizualność, jak sądzę, oznacza w tym ujęciu dominujące normy obrazowania i patrzenia, które mają dyscyplinujący charakter, określają bowiem sposób, w jaki (szeroko postrzegana) władza wykorzystuje wizualność do umacniania swej pozycji. Tak rozumiane reżimy czy sposoby widzenia formułują sposoby prezentowania rzeczywistości i tym samym warunkują jej społeczne postrzeganie ${ }^{22}$. Krótko mówiąc, determinują między innymi, kto ma prawo do patrzenia i bycia widzialnym (np. omijanie wzrokiem rdzennych społeczności) oraz które zjawiska i problemy są widokiem zakazanym (tj. klimatyczne koszty działań międzynarodowych korporacji). Taktyki i strategie opozycyjne wobec tych hegemonicznych praktyk, nazwanych tutaj kolonialnymi, mają więc w zamierzeniu podważenie obowiązującego porządku. Stanowią akt jednocześnie polityczny i etyczny, opowiadają się bowiem po stronie marginalizowanych, poszkodowanych czy nieuprzywilejowanych podmiotów.

Opisane przez Demosa działania aktywistów unaoczniają i „odbijają” obrazy władzy (dosłownie za pomocą luster), w zamian proponując własne. Prowokują do krytycznego patrzenia, między innymi przez rozpowszechnianie wiedzy o niewidzialnych czy też po prostu niedostrzegalnych aspektach opresyjnej polityki. Ponadto opisane grupy wprowadzają w życie - i w strefę widzialności - alternatywny model organizacji świata, międzyludzkich relacji i podzielanych wartości. Dlatego Demos nazywa je kreatywnymi ekologiami kolektywnego oporu (creative ecologies of collective resistance), kładąc nacisk na praktykowanie przez aktywistów zmiany systemowej i ćwiczenie alternatywnych rzeczywistości, które pozwala zwizualizować coś, co wydaje się niemożliwe ${ }^{23}$.

Michael Taussig, zdający zaangażowaną relację z etnograficznych badań ruchu Occupy Wall Street w nowojorskim parku Zuccottiego, podobnie opisał stosowane

21 T.J. Demos, The Great Transition: The Arts and Radical System Change, „e-flux”, https://www.e-flux. com/architecture/accumulation/122305/the-great-transition-the-arts-and-radical-system-change/ (dostęp: 20.09.2018). Autor analizuje kulturę wizualną antropocenu m.in. w publikacjach: Against the Anthropocene: Visual Culture and Environment Today, Sternberg Press, Berlin 2017; Decolonizing Nature: Contemporary Art and the Politics of Ecology, Sternberg Press, Berlin 2016.

22 M. Jay, Scopic Regimes of Modernity, w: H. Foster (red.), Vision and Visuality: Discussions in Contemporary Culture, Bay Press, Seattle 1988; J. Berger, Sposoby widzenia, przeł. M. Bryl, Fundacja Aletheia, Warszawa 2008

23 Zgodnie z klasyczną już wypowiedzią Slavoja Žižka, który twierdzi, że łatwiej wyobrazić sobie koniec świata niż koniec kapitalizmu. 
metody protestu i sposób jego organizacji. Brak hierarchiczności oraz jasno zdeklarowanych i zamanifestowanych postulatów ruchu Occupy dla wielu komentatorów stanowił przedmiot krytyki i wyjaśnienie ,porażki” protestujących, dla Taussiga był to jednak akt suwerenności, znak odrzucenia obowiązujących i narzuconych formuł komunikacji. Antropolog opisywał mechanizmy wypracowanego języka protestu, który charakteryzuje przekształcanie własnych słabości i niedostatków w siłę i atut:

Stosujemy swoją magię przeciw ich magii. Oni mają gaz pieprzowy. My paloną szałwię. Oni zakazują mikrofonu. My mamy ludzki mikrofon. Zakazują namiotów. Robimy improwizowane namioty, które nie są namiotami, ale tym, czego używali nomadzi przed North Face'em. Oni stawiają budynki wyższe od egipskich piramid, ale to one właśnie sprawiają, że nasze bębnienie rozchodzi się głośniej, a nasze nocne projekcje obrazów i maili są jeszcze bardziej widoczne i magiczne na megaekranach ich gigantycznych fasad. Każdy dzień, każdy tydzień przynosi kolejne deterytorializacje $\mathrm{w}$ reakcji na ich reterytorializacje. Zakazują paliwowych generatorów prądu, których używamy do ładowania komputerów i telefonów komórkowych. Ustawiamy w zamian rowerową elektrownię elektryczną. Dzięki temu zamiast po prostu się gapić i robić zdjęcia, ludzie włączają się do ruchu, stają się dionizyjscy, nie tylko apollińscy, siadają na siodełko i pedałują jak szaleni ${ }^{24}$.

Zarówno Demos, jak i Taussig zwracają uwagę na pomysłowe i subwersywne wykorzystanie przez manifestantów dostępnych narzędzi i obrócenie ich przeciwko władzy. Wskazują również na wdrażanie przez protestujących antykapitalistycznych reguł organizacji społecznego życia.

W moim przekonaniu jednak na tak zarysowanym tle wyróżnia się Liberate Tate, którego propozycja wydaje się zachowawcza, nie opiera się bowiem na obaleniu instytucji będących przecież częścią krytykowanego systemu, ale ,jedynie” na nich zreformowaniu. Alternatywny świat lepszej przyszłości widziany z perspektywy kolektywu zakłada więc istnienie instytucji nieraz krytykowanych za stanie na straży obowiązującego ładu, choć przewiduje dla nich nieco odmienne, bo zaangażowane, zadania i jednoznaczne wsparcie „słusznej” sprawy. Bunt kolektywu nie jest nakierowany na obalenie istniejącego porządku, ale na redystrybucję władzy w jego ramach.

Projektowana przez Liberate Tate rola galerii jest programowo zbieżna z propozycją nowej definicji muzeów ${ }^{25}$, opracowywaną w międzynarodowym środowisku muzealników ICOM (International Council of Museums) od 2016 roku. Zakłada ona między innymi aktywną pracę wokół wyzwań współczesności, której przyświecają cele sprawiedliwości społecznej, globalnej równości i dobrostanu planety. Warto jednak dodać, iż wspomniana definicja ma charakter ideacyjny, stanowi raczej wykaz

24 M. Taussig, Jestem tak wściekty, że zrobiłem transparent, „,Widok. Teorie i Praktyki Kultury Wizualnej” 2017, nr 17, http://www.pismowidok.org/pl/archiwum/2017/protest-obrazow/jestem-tak-wsciekly-ze-zrobilem-transparent (dostęp: 10.12.2018).

25 Zob. https://icom.museum/en/activities/standards-guidelines/museum-definition/(dostęp: 1.09.2019). Brzmienie nowej definicji zostało poddane pod głosowanie podczas Konferencji Generalnej ICOM we wrześniu 2019 roku, w którego rezultacie zdecydowano o dalszych pracach nad ostateczną treścią sformułowania. 
wytycznych i postulowanych zakresów oraz form organizacji muzeów niż rzeczywisty model funkcjonowania większości z nich. Mając na uwadze sieć polityczno-ekonomicznych zależności, w jakie uwikłane są placówki muzealne, założenie takiego profilu działalności instytucji z pewnością można określić jako utopijne. Nie deprecjonuje to jednak, w moim przekonaniu, prób jego osiągnięcia.

\section{Sztuka protestu / sztuka perswazji}

Liberate Tate prowadzi dwutorową zarówno wobec instytucji kultury, jak i firmy reprezentującej przemysł naftowy, którą klamrowo łączy zagadnienie korporacyjnej filantropii dotującej program galerii. Najlepiej opisuje je termin artwashing ${ }^{26}$, obejmujący szeroko rozumiane praktyki wykorzystujące sztukę do wzmocnienia bądź uszlachetnienia kapitału symbolicznego kontrowersyjnych firm. Korporacje posługujące się strategią artwashingu dzięki współpracy z renomowanymi instytucjami kultury i sztuki oraz stosunkowo niewielkim kosztem (zaskakująco niewielkim w przypadku Tate Gallery) zyskują wsparcie wizerunkowe i uprawomocnienie własnej działalności. Problematyczność mecenatu bywała często ignorowana bądź bagatelizowana, o czym świadczą słowa Nicolasa Seroty, byłego dyrektora Tate, który po wycieku ropy na platformie Deepwater Horizon stwierdził: „Wszyscy zdajemy sobie sprawę, że w tej chwili mają trudności [koncern BP - przyp. K.M.], ale nie porzucacie swoich przyjaciół, gdy - jak uważacie - mają chwilowe problemy"27. W marcu 2016 roku firma British Petroleum ogłosiła zerwanie 26-letniej współpracy z Tate Gallery, jako uzasadnienie tej decyzji podając „wymagające środowisko biznesowe" ${ }^{28}$. Długotrwała perswazja i protest okazały się więc skutecznym mariażem sztuki i aktywizmu, które wykorzystano jako narzędzie zmiany społecznej.

Problematyzacja relacji kryjących się za terminem artywizmu była już wielokrotnie podejmowana (skupiała się zwłaszcza wokół zagadnienia użyteczności sztuki $^{29}$ ). W tym względzie warto skoncentrować się na propozycji Gregory'ego Sholette'a przedstawianej w książce Delirium and Resistance: Activist Art and the

26 Termin pierwotnie pojawił się w kontekście analizy roli sztuki w procesach gentryfikacyjnych Los Angeles. Por. M. Evans, Artwash: Big Oil and the Arts, Pluto Press, London 2015. Autorka jest jedną z założycielek Liberate Tate.

27 N. Serota, Interview: Sir Nicholas Serota. The Man Who Turned the Tate Modern, https://www.thejc. com/culture/interviews/interview-sir-nicholas-serota-1.16648 (dostęp: 4.06.2017)

28 N. Clark, BP to End Controversial Sponsorship of Tate in 2017, „The Independent”, https://www. independent.co.uk/arts-entertainment/art/news/bp-to-end-controversial-sponsorship-of-tate-in2017-a6923471.html (dostęp: 3.06.2017).

29 W literaturze polskojęzycznej m.in. T. Załuski (red.), Skuteczność sztuki, Muzeum Sztuki w Łodzi, Łódź 2014. 
Crisis of Capitalism, poświęconej związkom sztuki aktywizmu z systemem neoliberalnym ${ }^{30}$.

Sholette jest autorem koncepcji ,ciemnej materii świata sztuki”"31, metafory, za pomocą której opisuje jego nierozpoznaną część, twórców wykluczonych z oficjalnego i elitarnego obiegu. Niewidoczni artyści stanowią 99-procentową część systemu $\mathrm{i}$, co szczególnie istotne, podstawę umożliwiającą jego istnienie i funkcjonowanie ${ }^{32}$. Ciemną materię tworzą bowiem zarówno aspirujący, jak i odrzucający establishment, zapomniani i zmuszeni do ograniczenia działalności artystycznej do pewnego rodzaju hobby, studenci i absolwenci szkół artystycznych, pracownicy „obsługi”, na przykład produkujący wystawy, publiczność galerii itd., a także aktywiści, których zrodziła opresyjność systemu. Relacje wewnątrz świata sztuki mogą więc być opisane za pomocą złożonych procesów współistnienia, opartych na eksploatacji i wykluczeniu.

Kolejnym pojęciem wykorzystywanym przez Sholette'a jest termin ,sztuka obnażona" (bare art), który umożliwia analizę uległości sztuki wobec kapitalizmu i demaskację skutków wzajemnych zależności ${ }^{33}$. Przykładowo pokazuje, jak kryzys ekonomiczny w 2008 roku przysłużył się interesom finansowej elity i jednocześnie wzmocnił pozycję sztuki, która stała się bezpieczną i przewidywalną przestrzenią inwestycji.

Oba zjawiska - ciemna materia oraz sztuka obnażona - wyznaczają ramy działania aktywistów i sytuują ich instytucjonalne relacje w ciekawym kontekście. Gregory Sholette zwraca uwagę na paradoksalne miejsce sztuki określanej jako „społeczna praktyka" w ramach oficjalnego obiegu. Twórczość aktywistów lub inaczej: sztuka społecznie i politycznie zorientowana jest akceptowana przez establishment i przez niego przejmowana (co poświadczają nagrody i wystawy jej poświęcone), choć jednocześnie aktywnie podważa i destabilizuje struktury, w ramach których funkcjonuje. Świat sztuki to nieubłagany aparat przechwytywania ${ }^{34}$, który „absorbuje opór i dąży do jego neutralizacji, jednak nie zawsze mu się to udaje" ${ }^{35}$. Amalgamat sztuki i polityczności przypomina więc autorowi ,deliryczny stan oporu i podporządkowania”"

Z perspektywy interpretacji kolektywu „uwalniającego” galerie Tate szczególnie interesujące wydaje się właśnie to napięcie, a także wskazówka przedstawiona przez Sholette'a dotycząca aktywizmu krytycznego wobec struktur sztuki. Jest nią

30 G. Sholette, Delirium and Resistance: Activist Art and the Crisis of Capitalism, Pluto Press, London 2017.

31 Przedstawionej w innej publikacji: G. Sholette, Dark Matter: Art and Politics in the Age of Enterprise Culture, Pluto Press, London 2011.

32 Więcej o sposobach utrzymywania i reprodukowania świata sztuki przez jego ciemną materię: G. Sholette, Ciemna materia świata sztuki, „Notes na 6 tygodni” 12.2014-1.2015, nr 97, s. 114-116.

33 G. Sholette, Delirium and Resistance..., s. 53-77.

34 Ibidem, s. 50.

35 Ibidem, s. 25.

36 Sholette używa angielskiego terminu subsumption, który w języku polskim funkcjonuje na gruncie prawnym jako ujęcie konkretnego przypadku w ramy ogólniejszej reguły. Zdecydowałam się na użycie pojemniejszego terminu ,podporządkowanie”. 
„program kradzieży i długoterminowego buntu, których zamierzeniem jest zerwanie i ponowne przywłaszczenie instytucjonalnej władzy w celach politycznych" ${ }^{37}$. Kluczowe w owym programie jest przesunięcie nastawienia wobec instytucjonalnych struktur, które nie są już traktowane jako cel czy opozycyjny przeciwnik, lecz jako środek aktywistycznych zmagań.

Strategia grupy Liberate Tate opiera się także na perswazyjnej krytyce instytucji sztuki i zdecydowanym proteście wobec korporacji naftowej degradującej środowisko i wyzyskującej zasoby naturalne. Oba cele są ze sobą powiązane. Taktyka protestu przeciw międzynarodowej firmie bazuje na krytycznej analizie funkcjonowania dotowanej przez koncern galerii, kampania opozycyjna wobec BP odbywa się więc za pośrednictwem muzeum. Jej celem jest pozbawienie koncernu współpracy w zakresie mecenatu, legitymizującej i wspierając wizerunek firmy. Brytyjskie przedsiębiorstwo naftowe ogłosiło wygaśnięcie umowy dotacyjnej wobec sieci galerii Tate, nadal jednak sponsoruje inne muzea brytyjskie, a więc znów: opór i podporządkowanie.

Decydujące $\mathrm{w}$ analizie formy sprzeciwu grupy jest jednak zwrócenie uwagi na próby przezwyciężenia tego impasu, sprawienia, by opór wchłonął podporządkowanie. Podejmowane są one na drodze kształtowania wspólnoty, budowania relacji i poszukiwania sojuszy. Kwestie kulturowego oporu realizowanego pod postacią generowania społecznych więzi opisuje między innymi Rafał Drozdowski. Polski socjolog koncentruje się na strategiach niezgody opartych na dobrowolnej dezindywidualizacji, bowiem to właśnie rosnący indywidualizm uznaje za jedno z największych społecznych zagrożeń ${ }^{38}$. Opisując je, wymienia więziotwórczą i wspólnotową praktykę, której celem jest rozwijanie kompetencji społecznych, na przykład krytycznej interpretacji populizmu. Zwraca również uwagę na uwikłanie oporu w system będący przedmiotem krytyki, istotne dla niego jest:

nie tyle utożsamianie go [oporu - przyp. K.M.] ze strategiami zamiast, przeciw lub pomimo, ile ze strategiami, które od początku przyjmują, że są elementami jakiejś koniunkcji i które swój „oporowy” charakter pojmują jako konsekwentną kontrolę nad poczynaniami drugiej strony, jako zobowiązanie do mobilizowania jej do coraz skuteczniejszych i zarazem coraz bardziej uczciwych społecznie i politycznie działań ${ }^{39}$.

Wspólnotowość jest praktykowana na poziomie samego kolektywu, choć w tym kontekście koncepcja Drozdowskiego wymaga pewnego uzupełnienia. Dezindywidualizacja jako forma oporu okazuje się bowiem dość romantycznym założeniem,

37 Ibidem, s. 45.

38 Jest to z pewnością dyskusyjna teza, jednak wydaje się użyteczna zwłaszcza w kontekście działań aktywistów związanych z ochroną środowiska, przekraczaniem partykularnych interesów i wspólną pracą na rzecz dobrostanu planety.

39 R. Drozdowski, Strategie refleksyjnej dezindywidualizacji jako nowa postać kultury oporu?, w: W. Kuligowski, A. Pomieciński (red.), Oblicza buntu. Praktyki i teorie sprzeciwu w kulturze współczesnej, Wydawnictwo Poznańskie, Poznań 2012, s. 129. 
jeśli nie weźmiemy pod uwagę procesów, w jakich formułuje się kolektyw, hierarchii, które istnieją w jej ramach, czy też - powołując się na Sholette'a - stopnia oporu i podporządkowania jego członków.

Liberate Tate kładzie szczególny nacisk na budowanie sojuszy, poszukując wsparcia zarówno wśród „wysoko pozycjonowanych” (takich jak instytucja muzeum, której siły w rozpowszechnianiu i legitymizacji określonych wartości nie sposób przecenić), jak i innych grup aktywistów oraz indywidualnych podmiotów. Inicjatywą, która w mojej ocenie najlepiej kondensuje dezindywidualizacyjną ambicję grupy, jest projekt Birthmark. Zapis na ciele poszerzającej się grupy ochotników odtwarza i uwidacznia postępujący charakter czynników przyczyniających się do zmian klimatu. Na poziomie artywistycznych strategii sygnalizuje zwrot społeczny, otwarcie i zaangażowanie nowych kręgów odbiorców. Choć zaangażowanie to ogranicza się do powtórzenia gestu artystów, to jednak rozsadza opozycję instytucja - artyści publiczność.

Opisane zależności pomiędzy sztuką, aktywizmem i współczesnym kapitalizmem najlepiej podsumowuje gest przechwytywania. Liberate Tate, które jednocześnie nim operuje i jemu podlega, próbuje pokonać patowe uwikłanie. Strategia grupy pokazuje, że myślenie o instytucji i próby jej zmiany mogą się dokonać tylko dzięki włączeniu w działania szerokich grup odbiorców, natomiast przyszłość „po” kapitalocenie może zainicjować radykalny i masowy sprzeciw wobec jego beneficjentów.

\section{Bibliografia}

Berger J., Sposoby widzenia, przeł. M. Bryl, Fundacja Aletheia, Warszawa 2008.

Bhabha H., Mimikra i ludzie. O dwuznaczności dyskursu kolonialnego, przeł. T. Dobrogoszcz, „Literatura na Świecie” 2008, nr 01-02 (438-439).

Demo A.T., The Guerrilla Girls'Comic Politics of Subversion, „,Women's Studies in Communication" 2000, vol. 23.

Drozdowski R., Strategie refleksyjnej dezindywidualizacji jako nowa postać kultury oporu?, w: W. Kuligowski, A. Pomieciński (red.), Oblicza buntu. Praktyki i teorie sprzeciwu w kulturze współczesnej, Wydawnictwo Poznańskie, Poznań 2012.

Evans M., Artwash: Big Oil and the Arts, Pluto Press, London 2015.

Fraser A., From the Critique of Institutions to an Institution of Critique, „Artforum” 2005 (September), vol. 44, iss. 1.

Jay M., Scopic Regimes of Modernity, w: H. Foster (red.), Vision and Visuality: Discussions in Contemporary Culture, Bay Press, Seattle 1988.

Lippard L.R., Trojan Horses: Activist Art and Power, w: B. Wallis (red.), Art after Modernism: Rethinking Representation, New Museum of Contemporary Art, New York 1984.

Malzacher F., Pisuar wraca do ubikacji. Symboliczna i bezpośrednia moc sztuki, w: S. Herbst, F. Mazacher (red.), Prawda jest konkretna. Artystyczne strategie w polityce. Podręcznik, Fundacja Bęc Zmiana, Warszawa 2018.

Mirzoeff N., Jak zobaczyć świat, przeł. Ł. Zaremba, Karakter - Muzeum Sztuki Nowoczesnej, Warszawa 2016. 
Patel R., Moore J., Tania natura, przeł. A.W. Nowak, P. Czapliński, w: P. Czapliński et al. (red.), O jeden las za daleko. Demokracja, kapitalizm i niepostuszeństwo ekologiczne w Polsce, Instytut Wydawniczy Książka i Prasa, Warszawa 2019.

Sholette G., Ciemna materia świata sztuki, „Notes na 6 tygodni” 12.2014-1.2015, nr 97.

Sholette G., Dark Matter: Art and Politics in the Age of Enterprise Culture, Pluto Press, London 2011.

Sholette G., Delirium and Resistance: Activist Art and the Crisis of Capitalism, Pluto Press, London 2017.

Załuski T. (red.), Skuteczność sztuki, Muzeum Sztuki w Łodzi, Łódź 2014.

\section{Źródła internetowe:}

Birthmark, http://www.liberatetate.org.uk/birthmark/ (dostęp: 1.09. 2018).

Clark N., BP to End Controversial Sponsorship of Tate in 2017, „The Independent”, https:// www.independent.co.uk/arts-entertainment/art/news/bp-to-end-controversial-sponsorship-of-tate-in-2017-a6923471.html (dostęp: 3.06.2017).

Demos T.J., The Great Transition: The Arts and Radical System Change, ,e-flux”, https:// www.e-flux.com/architecture/accumulation/122305/the-great-transition-the-arts-and-radical-system-change/ (dostęp: 20.09.2018).

Evans M., Smith K., Liberate Tate Activists Look Back on Six Years of Fighting BP Sponsorship. Interview by Benjamin Sutton, https://hyperallergic.com/288254/liberate-tate-activists-look-back-on-six-years-of-fighting-bp-sponsorship/ (dostęp: 10.07.2017).

Fossil Free Culture NL, Disobedient Art Can Win the Fight against Artwashing, https://gofossilfree.org/disobedient-art-wins-the-fight-against-artwashing/ (dostęp: 20.09.2018).

Jordan J., On Refusing to Prebend to Do Politics in a Museum, http://www.artmonthly.co.uk/ magazine/site/article/on-refusing-to-pretend-to-do-politics-in-a-museum-by-john-jordan-2010 (dostęp: 11.08.2018).

Khomami N., BP to End Tate Sponsorship after 26 Years, „The Guardian”, https://www. theguardian.com/artanddesign/2016/mar/11/bp-to-end-tate-sponsorship-climate-protests (dostęp: 10.08.2018).

Museum Definition, https://icom.museum/en/activities/standards-guidelines/museum-definition/ (dostęp: 1.09.2019).

Our Vision, https://www.tate.org.uk/about-us/our-priorities (dostęp: 3.09.2018).

Serota N., Interview: Sir Nicholas Serota. The Man Who Turned the Tate Modern, https://www. thejc.com/culture/interviews/interview-sir-nicholas-serota-1.16648 (dostęp: 4.06.2017).

Tate Report 2009-2010, https://www.tate.org.uk/download/file/fid/17029 (dostęp: 20.08.2018).

Taussig M., Jestem tak wściekty, że zrobiłem transparent, „Widok. Teorie i Praktyki Kultury Wizualnej” 2017, nr 17, http://www.pismowidok.org/pl/archiwum/2017/protest-obrazow/jestem-tak-wsciekly-ze-zrobilem-transparent (dostęp: 10.12.2018).

Ujma M., Krytyka instytucjonalna, http://magdalena-ujma.blogspot.com/2013/01/krytyka-instytucjonalna.html (dostęp: 2.07.2018). 